\title{
Red Wine administration to Apolipoprotein E-deficient Mice reduces their Macrophage-derived Extracellular Matrix Atherogenic Properties
}

\author{
MARIELLE KAPLAN and MICHAEL AVIRAM
}

Lipid Research Laboratory, Technion Faculty of Medicine, The Rappaport Family Institute for Research in the Medical Sciences, and Rambam Medical Center, Haifa, Israel.

\begin{abstract}
Proteoglycans (PGs) from the arterial extracellular matrix (ECM) contribute to the trapping of LDL and oxidized LDL (Ox-LDL) in the arterial wall, a phenomenon called "lipoprotein retention". Moreover, we have shown that subsequent to their binding to the matrix, LDL and Ox-LDL are taken up by macrophages. Oxidative stress significantly increases macrophage secretion of ECM-PGs, lipoprotein binding to the ECM and the uptake of ECM-retained lipoproteins by macrophages. The aim of the present study was to determine whether red wine administration to atherosclerotic mice would affect their peritoneal macrophage-derived extracellular matrix properties, such as the glycosaminoglycan content and the ability to bind LDL. In addition, we questioned the ability of LDL bound to the mice peritoneal macrophages-derived ECM to be taken up by macrophages. Red wine administration to atherosclerotic mice did not affect the mice peritoneal macrophages-derived ECM glycosaminoglycan content but it significantly reduced the mice peritoneal macrophages-derived ECM ability to bind LDL and the subsequent uptake of ECM-retained LDL by the macrophages. The present study thus clearly demonstrated the inhibitory effect of red wine consumption by $\mathrm{E}^{0}$ mice on their peritoneal macrophage-derived extracellular matrix atherogenic properties.
\end{abstract}

Key words: Antioxidants, atherosclerosis, extracellular matrix, macrophages, polyphenols, proteoglycans, red wine.

Abbreviations: CE: cholesterol ester; DMMB: 1,9-dimethylmethylene blue; ECM: extracellular matrix; $\mathrm{E}^{0}$ : apolipoprotein E deficient; FCS: fetal calf serum; GAG: glycosaminoglycan; LDL: low density lipoprotein; LDL-R: LDL receptor; LPL: lipoprotein lipase; MPM: mouse peritoneal macrophages; Ox-LDL: oxidized LDL; PBS: phosphate buffered saline; PGs: proteoglycans.

\section{INTRODUCTION}

The development of atherosclerotic lesion is initiated with the accumulation of cholesterol in monocyte-derived macrophages $(2,3)$ as well as with the retention of lipoproteins in the extracellular matrix of the subendothelial wall $(22,30)$. Extracellular matrix (ECM) contains collagen and elastic fibers embedded in a viscoelastic gel consisting of proteoglycans (PGs), hyaluronan and glycoproteins (29). Arterial ECM contributes to the trapping of LDL and oxidized LDL (Ox-LDL) in the arterial wall, a phenomenon called "lipoprotein retention" (7, 18, 31). Specifically, the PGs from the ECM were shown to be responsible for the entrapment of LDL and Ox-LDL in the arterial wall $(19,27)$. Moreover, we have shown that subsequent to their binding to the matrix, LDL and Ox-LDL are taken up by macrophages (20). ECM can be produced in vitro by arterial cells, including endothelial cells, smooth muscle cells and also by macrophages (19). The amount and composition of ECM produced by all major cells of the arterial wall, determine the extent of lipoprotein cellular uptake. We have demonstrated that under oxidative 
stress, the macrophage ECM-PG secretion, the binding of lipoproteins to the ECM and the uptake of the ECM-retained lipoproteins by macrophages, are all significantly increased (20).

The intake of flavonoids, which constitute one of the largest groups of antioxidant phytochemicals, was shown to be inversely related to morbidity and mortality from coronary heart disease (16) and this phenomenon could be associated with polyphenol-mediated fibrinolytic effects (24), vasodilator effects (8) and most important, antioxidant effects $(5,12)$. The bioavailability and metabolic modifications of flavonoids determine the antioxidative capacity of these potent antioxidants in vivo. Flavonoids can reduce LDL lipid peroxidation by acting as free-radical scavengers, as metal ion chelators, or by sparing LDL-associated antioxidants (10, 12). Flavonoids can also reduce macrophage oxidative stress by inhibition of cellular oxygenases (such as NADPH oxidase) and/ or by activating cellular antioxidants such as the glutathione system (25). The effect of flavonoids on LDL oxidation is determined, by their accumulation in the lipoprotein on one hand, and in arterial cells (such as macrophages) on the other hand $(10,11)$.

Red wine is a dietary source of polyphenols, such as flavonols, quercetin and myricetin, and 3-flavanols, catechin and epi(gallo)catechin. Following wine ingestion, some wine-derived polyphenols bind to the LDL particle and protect the lipoprotein against oxidation (9). In the presence of wine-derived flavonoids, the activity of HDL-associated paraoxonase (an esterase that hydrolyzes oxidized lipids) is preserved and thus further reduces the lipoprotein oxidative state $(14,21)$. Winepolyphenols, which accumulate in arterial wall cells such as macrophages, can protect them from lipid peroxidation and thus further reduce macrophage lipid peroxidation and cell-mediated oxidation of LDL, leading to attenuation in foam cell formation (4). Furthermore, wine administration to atherosclerotic mice (apolipoprotein $\mathrm{E}$ deficient mice) attenuates the development of atherosclerotic lesions in this animal model (15).
The aim of the present study was to determine whether red wine administration to atherosclerotic mice would affect their peritoneal macrophage-derived ECM properties, including their glycosaminoglycan (GAG) content and their ability to bind LDL. In addition, we questioned the effect of red wine on the cellular uptake of LDL bound to mouse peritoneal macrophages-derived ECM.

\section{EXPERIMENTAL DESIGN}

\section{Mice}

The study protocol was approved by the Committee for the supervision of animal experiments of the Technion Israel Institute of Technology (approval number IL-066$10-2001 / 04)$ and was conducted in accordance with the guiding principles in the care and use of laboratory animals.

Apolipoprotein $\mathrm{E}$ deficient $\left(\mathrm{E}^{0}\right)$ mice were provided by Dr. Jan Breslow (Rockefeller University, NY). $\mathrm{E}^{0}$ mice are widely used as an animal model for atherosclerosis as they develop severe hypercholesterolemia on a chow diet. $\mathrm{E}^{0}$ atherosclerotic mice at 4 weeks of age were assigned randomly into three groups; 5 mice in each group. The mice were supplemented for 5 weeks with the following substances that were added to their drinking water: (1) Placebo (water), (2) red wine $(0.125 \mathrm{ml}$ red wine Cabernet Sauvignon/mouse/day), (3) vitamin E (50 mg/mouse/day).

\section{Mouse peritoneal macrophages isolation}

Mouse peritoneal macrophages (MPM) were harvested from the peritoneal fluid of $\mathrm{E}^{0}$ mice, 4 days after intraperitoneal injection into each mouse of $3 \mathrm{ml}$ of thioglycolate $(24 \mathrm{~g} / \mathrm{l})$ in saline. The cells (10-20*106/mouse) were washed, dispensed into plastic Petri dishes and incubated in a humidified incubator $\left(5 \% \mathrm{CO}_{2}, 95 \%\right.$ air) for $2 \mathrm{~h}$ at $37^{\circ} \mathrm{C}$.

\section{Extracellular matrix preparation}

Macrophages (MPM from $\mathrm{E}^{0}$ mice) were cultured for 4 days at $37^{\circ} \mathrm{C}$ in DMEM 
containing $10 \%$ fetal calf serum (FCS). Then, cells were removed using $0.5 \%$ Triton X-100 and 20mM $\mathrm{NH}_{4} \mathrm{OH}$. Dishes coated with the ECM were then washed with phosphate buffered saline (PBS) and kept at $4^{\circ} \mathrm{C}$ for use within two weeks (28). The macrophage ECM remained intact and was free of cellular elements. The above treatment completely removes the cell layer leaving behind only the matrix secreted by the cells. ECM protein content was assessed by the Lowry assay.

\section{ECM Glycosaminoglycans determination}

Macrophage GAG content was analyzed using the 1,9-dimethylmethylene blue (DMMB) spectrophotometric assay for sulfated glycosaminoglycans (26).

Degradation and cell-association of ECMretained lipoproteins by macrophages

Dishes coated with the macrophagederived-ECM, were preincubated with 8 $\mathrm{mg} / \mathrm{ml}$ of lipoprotein lipase (LPL) for 1 hour at $4^{\circ} \mathrm{C}$. After 3 washes with $\mathrm{PBS}$, radioiodinated-LDL (25 $\mathrm{mg}$ of protein $/ \mathrm{ml}$ ) was added for 4 hours at $37^{\circ} \mathrm{C}$. Finally, after 3 more washes with PBS, fresh macrophages were seeded onto the ECM layer in presence of the cellular activator phorbol myristate acetate $(100 \mathrm{nM})$ for 18 hours at $37^{\circ} \mathrm{C}$. Cell-mediated hydrolysis of LDL protein was assayed by determination of the trichloroacetic acid soluble, chloroform-insoluble radioactivity in the incubation medium (20). Degradation of lipoproteins, that were added to control empty plates, was minimal $(<10 \%)$ and was always subtracted from the degradation rates of the ECM-retained lipoproteins.

\section{Statistics}

$\mathrm{T}$ test was performed for all statistical analyses. Results are given as mean $\pm \mathrm{SD}$

\section{RESULTS}

Mouse peritoneal macrophages (MPMs) were harvested from the 3 groups (placebo, red wine-treated and vitamin E-treated) of apolipoprotein $\mathrm{E}$ deficient $\left(\mathrm{E}^{0}\right)$ mice and these cells were used to produce ECM. ECM derived from the $\mathrm{E}^{0}$ harvested MPMs was analyzed for GAG content, and its ability to bind LDL. In addition, we analyzed the ability of LDL-bound to ECM to be taken up by J-774 A.1 macrophages.

The GAG content of the ECM derived from MPM was not affected either by red wine treatment, or by vitamin $\mathrm{E}$ treatment, in comparison to the placebo-treated mice (Fig. 1A).

ECM obtained for the 3 groups of mice (placebo, red wine-treated and vitamin Etreated) were then incubated with ${ }^{125}$ I-LDL to compare their ability to bind LDL. The binding of LDL to the macrophage-derivedECM was significantly reduced by $77 \%$ following mice treatment with red wine but by only $18 \%$ following mice treatment with vitamin $\mathrm{E}$, in comparison to the placebo-treated mice (Fig. 1B).

Finally, LDL that was retained to ECM derived from MPM was incubated with $\mathrm{J}$ 774 A.1 macrophages in the presence of 100 nM PMA (cellular activator), in order to determine the ECM-retained-LDL cellular uptake by the macrophage cell-line. Macrophage degradation of ECM-retained LDL was decreased by $56 \%$ when the ECM was prepared from MPMs harvested from red wine-treated mice in comparison to ECM prepared from MPM harvested from placebo-treated mice (Fig. 1C). In contrast, macrophage degradation of LDL that was retained to ECM from MPMs harvested from vitamin E-treated mice was similar to that of placebo-treated mice (Fig. 1C).

\section{DISCUSSION}

The present study clearly demonstrated the inhibitory effect of red wine consumption by $\mathrm{E}^{0}$ mice on their peritoneal macrophagederived ECM atherogenic properties, such as LDL binding to the ECM and its subsequent uptake by macrophages, leading to an inhibitory effect on foam cell formation (Fig. 2).

ECM produced by the cells of the arterial wall participated in the 

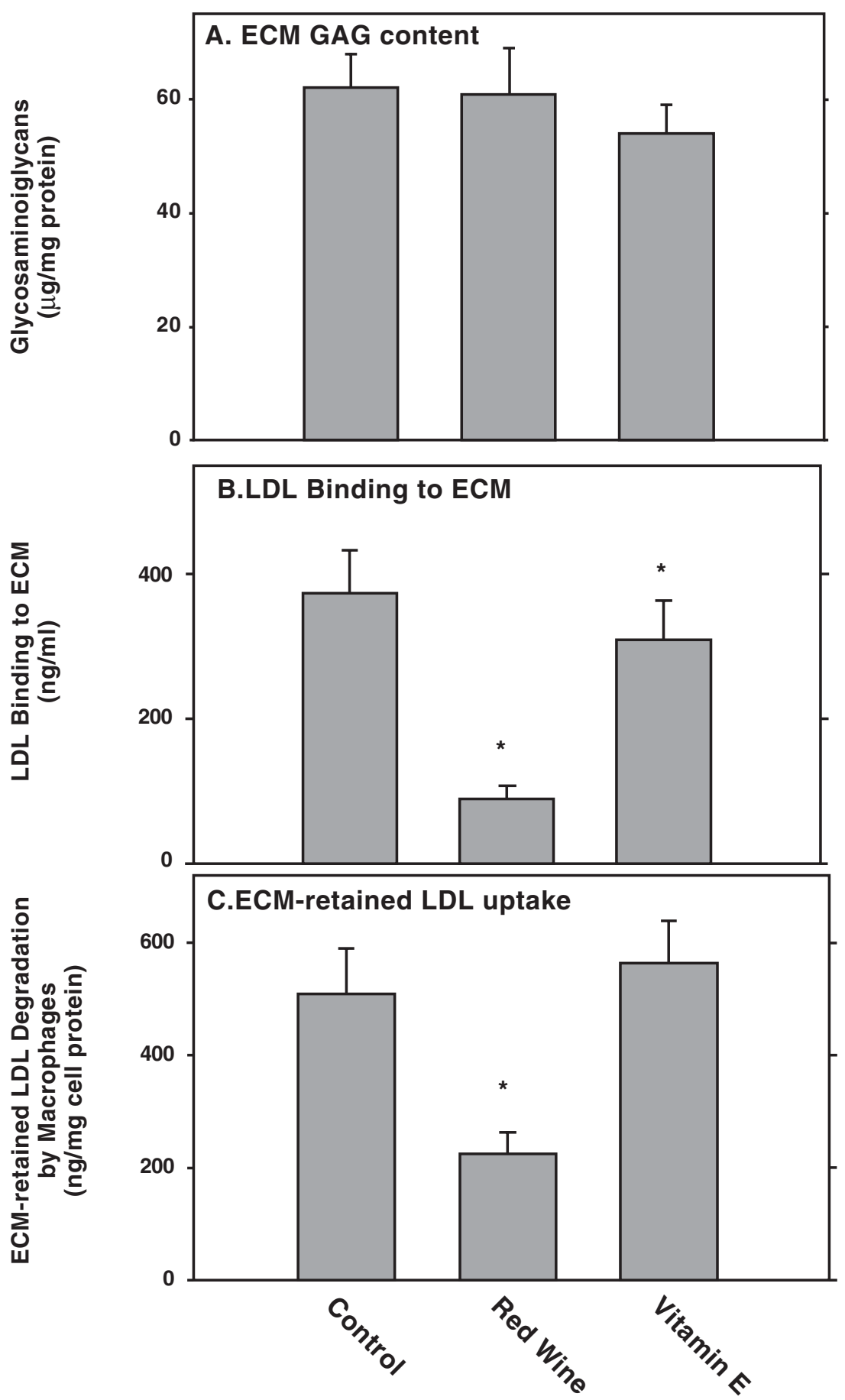

Figure 1. The effect of red wine or vitamin $E$ supplementation to apolipoprotein $E$ deficient $\left(E^{0}\right)$ mice on their peritoneal macrophage derived extracellular matrix (ECM) atherogenicity.

ECM prepared from mouse peritoneal macrophages (MPM) that were isolated from 3 groups of apolipoprotein E deficient mice (red wine-treated, vitamin-E treated and placebo-treated) were analyzed for their glycosaminoglycan content (A), and their ability to bind LDL (B). This latter ECM-retained LDL was used to analyze the lipoprotein uptake by J-774 A.1 macrophages (C). Results are given as mean $\pm \mathrm{SD}, * \mathrm{p}<0.01(\mathrm{n}=5)$. 


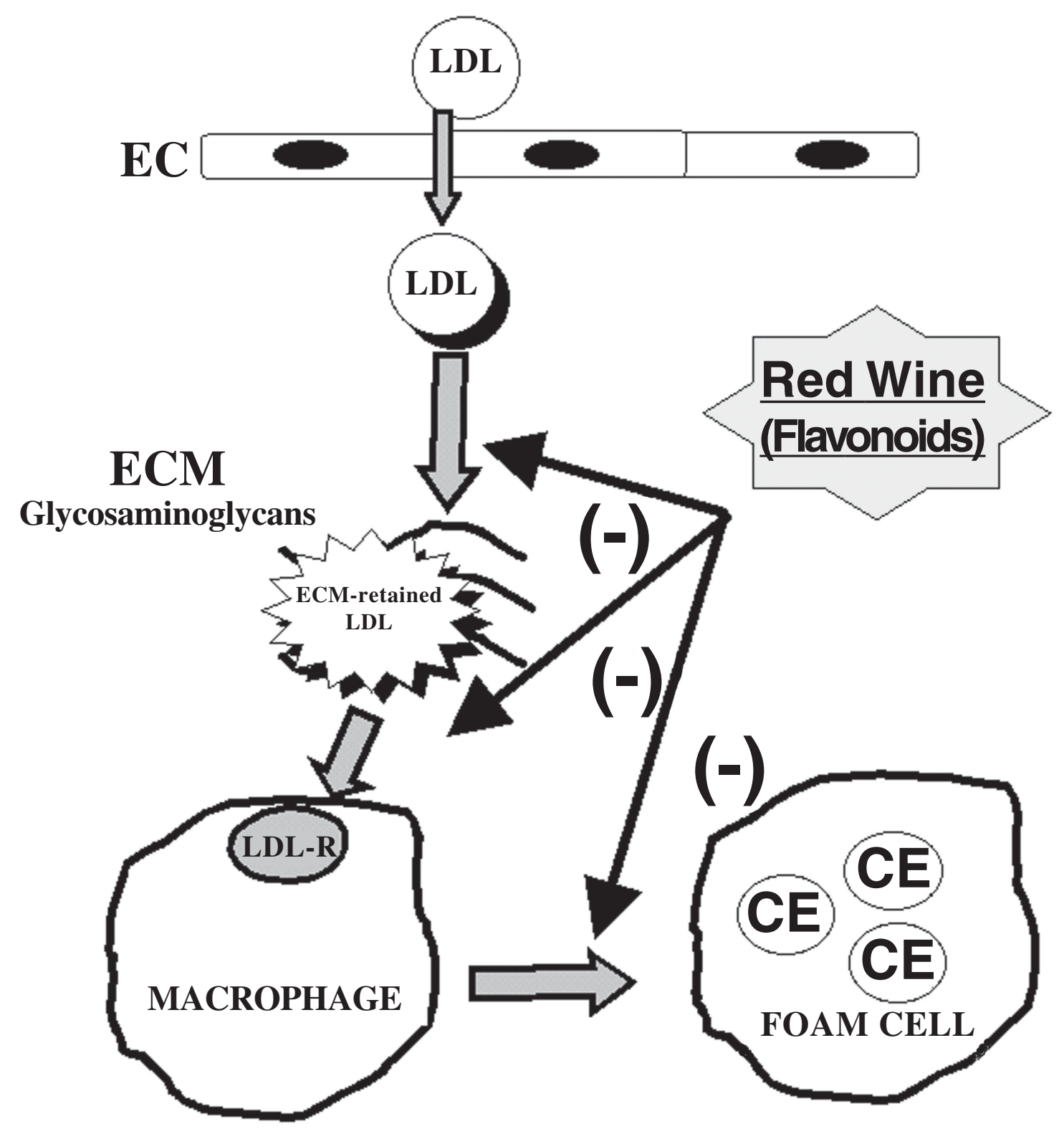

Figure 2. Red wine supplementation to apolipoprotein $\mathrm{E}$ deficient $\left(\mathrm{E}^{0}\right)$ mice inhibits LDL retention to the peritoneal macrophage derived-extracellular matrix (ECM).

Following red wine consumption, flavonoids present in red wine can reduce retention of LDL to the ECM, thus inhibiting the macrophage uptake of ECM-retained LDL, and therefore leading to a reduction in macrophage cholesterol accumulation and foam cell formation. EC: Endothelial cell, ECM: Extracellular matrix, LDL: Low density lipoprotein, CE: cholesterol ester, LDL-R: LDL receptor. 
development of the atherosclerotic lesion (30). ECM-derived-GAGs are able to trap LDL in the arterial wall, a process called "LDL retention" (7, 18, 31). Following its retention in the arterial wall, the lipoprotein becomes more susceptible to oxidation, and it is taken up by arterial cells such as macrophages at enhanced rate $(20,27)$. Thus, modulation of the ECM content (especially its GAG content) could affect the ECM atherogenic properties.

In the present study we have shown for the first time that although total GAGs content of the macrophages derived ECM was not affected by red wine treatment, it significantly reduced the ability of the matrix layer to bind LDL. More important, this reduction in macrophage LDL binding was associated with a marked decrement in the subsequent uptake of the ECM-retained LDL by macrophages. Vitamin E, as opposed to red wine flavonoids caused only a slight reduction in LDL retention to the macrophages derived ECM, and did not affect the ECM-retained LDL uptake by macrophages.

Once LDL is trapped in the arterial wall and isolated from the plasma antioxidantrich environment, the lipoprotein becomes more susceptible to oxidation. Oxidation of LDL then, results in its separation from the ECM, followed by the lipoprotein $\left(\mathrm{Ox}^{-}\right.$ LDL) uptake by macrophages. The inhibitory effect of red wine on LDL retention thus affects its subsequent oxidation and the cellular uptake of the oxidized lipoprotein. In addition, red wine supplementation to $\mathrm{E}^{0}$ mice also reduced macrophage uptake of the ECM-retained LDL. The ability of red wine to affect LDL retention to ECM and its subsequent uptake by arterial wall cells, in spite of the fact that it did not affect total GAG content in the ECM, can be explained by the fact that ECM is composed of several classes of GAG. The effect of red wine consumption on the ECM-GAGs could thus be due to their composition rather than to the total GAG content.

Red wine supplementation to apolipoprotein E-deficient mice was previously shown to reduce oxidative stress, both in serum and in peritoneal macrophages $(1,9,15)$. However the inhibitory effect of red wine on the retention of LDL to the ECM may not be related to additional effects of red wine besides its antioxidant effects (6), as vitamin $\mathrm{E}$ was ineffective.

The ability of red wine flavonoids to attenuate atherogenesis is determined by the capacity of these substances to scavenge reactive oxygen/nitrogen species (and not a single type of free radical) as shown by comparing several different varieties of red wine (17). Different types of flavonoids exert different capacities to scavenge free radicals as we have recently shown (13).

In conclusion, red wine, in addition to its known anti-oxidative characteristics, also significantly reduces macrophage-derived ECM atherogenic properties. These properties contribute to the ability of red wine consumption to attenuate the development of atherosclerosis (23).

\section{REFERENCES}

1. AVIRAM M, HAYEK T, FUHRMAN B (1997) Red wine consumption inhibits LDL oxidation and aggregation in humans and in atherosclerotic mice. Biofactors 6: 415-419.

2. AVIRAM M (1999) Macrophage foam cell formation during early atherogenesis is determined by the balance between pro-oxidants and anti-oxidants in arterial cells and blood lipoproteins. Antioxid Redox Signal 1: 585594.

3. AVIRAM M (2000) Review of human studies on oxidative damage and antioxidant protection related to cardiovascular diseases. Free Radic Res 33 Suppl: S8597.

4. AVIRAM M, FUHRMAN B (2002) Wine flavonoids protect against LDL oxidation and atherosclerosis. In: Alcohol and Wine in health and disease. Annals of the New York Academy of Sciences. 957: 146-161.

5. AVIRAM M, FUHRMAN B (2003) Wine Flavonoids, LDL Cholesterol Oxidation and Atherosclerosis. In Sandler M, Pinder R (eds) Wine: A Scientific Exploration, $1^{\text {st }}$ ed. Taylor \& Francis, 140-159.

6. BARTOS V (2002) Atherosclerosis, alcohol and diabetes. Vnitr Lek 48: 529-533.

7. CAMEJO G, HURT-CAMEJO E, WIKLUND O, BONDJERS G (1998) Association of apoB lipoproteins with arterial proteoglycans: Pathological significance and molecular basis. Atherosclerosis 139: 205-222.

8. CORDER R, BOUTHWAITE J (2001) Endothelin-1 synthesis reduced by red wine. Nature 414: 863-864.

9. FUHRMAN B, LAVY A, AVIRAM M (1995) Consumption of red wine with meals reduces the susceptibility of human plasma and LDL to undergo lipid peroxidation Am J Clin Nutr 61: 549-554.

10. FUHRMAN B, AVIRAM M (2001) Polyphenols and Flavonoids Protect LDL against Atherogenic Modifications. In: Handbook of Antioxidants: 
Biochemical, Nutritional and Clinical Aspects, $2^{\text {nd }}$ Edition, Ch. 16, pp 303-336.

11. FUHRMAN B, AVIRAM M (2001) Anti-atherogenicity of nutritional antioxidants. IDrugs 4: 82-92.

12. FUHRMAN B, AVIRAM M (2001) Flavonoids protect LDL from oxidation and attenuate atherosclerosis. Curr Opin Lipidol 12: 41-48.

13. FUHRMAN B, VOLKOVA N, AVIRAM M (2001) White wine with red wine-like properties: increased extraction of grape skin's-polyphenols improves the antioxidant capacity of the derived white wine. J. Agric. Food Chem. 49: 3164-3168.

14. FUHRMAN B, AVIRAM M (2002) Preservation of paraoxonase activity by wine by wine flavonoids: possible role in protection of LDL from lipid peroxidation. Ann NY Acad Sci 957: 321-324.

15. HAYEK T, FUHRMAN B,VAYA J, ROSENBLAT M, BELINKY P, COLEMAN R, ELIS A, AVIRAM M (1997) Reduced progression of atherosclerosis in the apolipoprotein E deficient mice following consumption of red wine, or its polyphenols quercetin or catechin, is associated with reduced susceptibility of LDL to oxidation and aggregation. Arterioscler Thromb Vasc Biol 17: 2744-2752.

16. HERTOG MG, KROMHOUT D, ARAVANIS C, BLACKBURN H, BUZINA R, FIDANZA F, GIAMPAOLI S, JANSEN A, MENOTTI A, NEDELJKOVIC S, et al. (1995) Flavonoid intake and long-term risk of coronary heart disease and cancer in the seven countries study. Arch Intern Med 155: 381386.

17. HOWARD A, CHOPRA M, THURNHAM D, STRAIN J, FUHRMAN B, AVIRAM M (2002) Red wine consumption and inhibition of LDL oxidation: what are the important components? Med Hypotheses 59: 101-104.

18. HURT E, BONDJERS G, CAMEJO G (1990) Interaction of LDL with human arterial proteoglycans stimulates its uptake by human monocyte-derived macrophages. J Lipid Res 31: 443-454.

19. KAPLAN M, AVIRAM M (1997) Oxidized LDL binding to a macrophage-secreted extracellular matrix. Biochem Biophys Res Comm 237: 271-276.

20. KAPLAN M, AVIRAM M (2001) Retention of oxidized LDL by the extracellular matrix proteoglycans leads to its uptake by macrophages: An alternative approach to studies on lipoprotein uptake. Arterioscler Thromb Vasc Biol 21: 386-393.

21. LAVY A, FUHRMAN B, MARKEL A, DANKNER G, BEN-AMOTZ A, PRESSER D, AVIRAM M (1994) Effect of dietary supplementation of red or white wine on human blood chemistry, hematology and coagulation: favorable effect of red wine on plasma high-density lipoprotein. Ann Nutr Metab 38: 287-294.

22. LUSIS AJ (2000) Atherosclerosis. Nature 407: 233241.

23. MUKAMAL KJ, CONIGRAVE KM, MITTLEMAN MA, CAMARGO CA JR, STAMPFER MJ, WILLETT WC, RIMM EB (2003) Roles of drinking pattern and type of alcohol consumed in coronary heart disease in men. N Engl J Med 348: 109-118.

24. RENAUD S, DE LORGERIL M (1992) Wine, alcohol, platelets, and the French paradox for coronary heart disease. Lancet 339: 1523-1526.

25. ROSENBLAT M, BELINKY P, VAYA J, LEVY R, HAYEK T, COLEMAN R, MERCHAV S, AVIRAM M (1999) Macrophage enrichment with the isoflavan glabridin inhibits NADPH oxidase-induced cell-mediated oxidation of low density lipoprotein. A possible role for protein kinase C. J Biol Chem 274: 13790-13799.

26. VAN DE LEST CHA, VERSTEEG EMM, VEERKAMP JH, VAN KUPPEUELT TH (1994) A spectrophotometric method for the determination of heparan sulfate. Biochim Biophys Acta 1201: 305-311.

27. VIJAYAGOPAL P, SRINIVASAN SR, RADHAKRISHANAMURTHY B, BERENSON GS (1992) Lipoprotein-proteoglycan complexes from atherosclerotic lesions promote cholesteryl ester accumulation in human monocytes/macrophages. Arterioscler Thromb 12: 237-249.

28. VLODAVSKY I, FOLKMAN J, SULLIVAN R, FRIEDMAN R, ISHAI-MICHAELI R, SASSE J, KLAGSBRUN M (1987) Endothelial cell-derived bFGF: Synthesis and deposition into subendothelial extracellular matrix. Proc Natl Acad Sci USA 84: 2292-2296.

29. WIGHT TN (1994) The extracellular matrix and atherosclerosis. Curr Opin Lipidol 6: 326-334.

30. WILLIAMS KJ, TABAS I (1995) The response to retention hypothesis. Arterioscler Thromb 15: 551-561.

31. WILLIAMS KJ, TABAS I (1998) The response-toretention hypothesis of atherogenesis reinforced. Curr Opin Lipidol 9: 471-474. 